\title{
COMUNICAÇÃO
}

\section{ENRAIZAMENTO DE MINIESTACAS DE ESPINHEIRA-SANTA (Maytenus ilicifolia Mart. ex Reissek) EM DIFERENTES SUBSTRATOS}

\author{
Rooting of espinheira-santa (Maytenus ilicifolia Mart. ex Reissek) \\ minicuttings on different substrates
}

\author{
Daniela Macedo de Lima1, Guilherme Nakao Tanno², Marivel Purcino3 \\ Luiz Antonio Biasi ${ }^{4}$, Katia Christina Zuffellato-Ribas ${ }^{5}$, Flavio Zanette ${ }^{6}$
}

\begin{abstract}
RESUMO
Pertencente à família Celastraceae, a espinheira-santa (Maytenus ilicifolia Mart. ex Reissek) é uma espécie medicinal nativa da região sul do Brasil, utilizadas no tratamento de gastrite e úlceras gástricas. Estudos sobre a produção de mudas por meio de estaquia demonstraram que esta espécie é considerada de difícil enraizamento. Objetivou-se, no presente trabalho, avaliar os efeitos de diferentes substratos no enraizamento de miniestacas de espinheira-santa. Miniestacas apicais foram coletadas a partir das brotações das minicepas de 10 meses de idade, mantidas em casa-de-vegetação e confeccionadas com $3 \mathrm{a} 4 \mathrm{~cm}$ de comprimento, mantendo-se duas folhas com a superfície reduzida à metade. O plantio foi realizado em caixas contendo areia e tubetes contendo casca de arroz carbonizada, Plantmax HT $^{\circledast}$ ou vermiculita de granulometria fina como substrato. As miniestacas foram mantidas em casa-de-vegetação com nebulização intermitente e 90 dias após o plantio, foram avaliadas as características: porcentagem de estacas enraizadas, número e comprimento médio de raízes, porcentagem de estacas com calos, sobrevivência e mortalidade. O delineamento experimental foi inteiramente casualizado, com 4 tratamentos e 4 repetições de 22 estacas por parcela. A análise estatística revelou que os substratos areia $(92,04 \%)$, casca de arroz carbonizada $(88,66 \%)$ e Plantmax HT $^{\circledR}(94,31 \%)$ apresentaram índices de enraizamento significativamente superiores à vermiculita $(78,41 \%)$, além de menores taxas de mortalidade, sendo que a propagação vegetativa de espinheira-santa por meio de miniestaquia é viável.
\end{abstract}

Termos para indexação: Maytenus ilicifolia, miniestaquia, planta medicinal.

\section{ABSTRACT}

Espinheira-santa (Maytenus ilicifolia Mart. ex Reissek), which belongs to the Celastraceae family, is a medicinal species native to the south region of Brazil, used in gastritis and gastric ulcer treatment. Studies about plant production by cutting have shown that this species is considered difficult to root. The purpose of this work was to evaluate the influence of different substrates on the rooting capacity of espinheira-santa minicuttings. Apical minicuttings with $3-4 \mathrm{~cm}$ and two half-cut leaves were collected from 10-month-old ministump sprouts kept in a greenhouse and planted on sand boxes and polypropylene tubes filled with carbonized rice hull, Plantmax $\mathrm{HT}^{\circledR}$ or fine granulated vermiculite. The minicuttings were kept in a greenhouse under intermittent mist. After 90 days, the following variables were evaluated: percentage of rooted cuttings, number and average length of roots per cutting, percentage of cuttings presenting calluses, survival and mortality rate. A completely randomized design of four treatments with 22 minicuttings per experimental unit and four replications was used. Statistical analysis revealed that sand $(92.04 \%)$, carbonized rice hulls $(88.66 \%)$ and Plantmax $\mathrm{HT}^{\circledR}(94.31 \%)$ presented significantly higher rooting capacity and lower mortality than vermiculite $(78.41 \%)$. Vegetative propagation of espinheira-santa by using minicuttings is viable.

Index terms: Maytenus ilicifolia, minicutting, medicinal plant.

(Recebido em 12 de julho de 2007 e aprovado em 19 de fevereiro de 2008)

\footnotetext{
'Bióloga, Doutora - Universidade Tecnológica Federal do Paraná/UTFPR - Campus Dois Vizinhos - Estrada para Boa Esperança, km 04 Comunidade São Cristóvão - 85660-000 - Dois Vizinhos, PR - danielamlima@utfpr.edu.br.

${ }^{2}$ Graduando em Agronomia - Universidade Federal do Paraná/UFPR - Rua dos Funcionários, 1540 - Juvevê - Cx. P. 19061 - $81531-990$ - Curitiba, PR guinata@hotmail.com

${ }^{3}$ Graduanda em Agronomia - Universidade Federal do Paraná/UFPR - Rua dos Funcionários, 1540 - Juvevê - Cx. P. 19061 - 81531 -990 - Curitiba, PR marivelpurcino@yahoo.com.br

${ }^{4}$ Engenheiro Agrônomo, Doutor - Departamento de Fitotecnia e Fitossanitarismo - Universidade Federal do Paraná/UFPR - Rua dos Funcionários, 1540 Juvevê - Cx. P. 19061 - 81531-990 - Curitiba, PR - biasi@ufpr.br

${ }^{5}$ Bióloga, Doutora - Departamento de Botânica - Universidade Federal do Paraná/UFPR - Setor de Ciências Biológicas - Centro Politécnico - Jardim das Américas - Cx. P. 19031 - 81531-970 - Curitiba, PR - kazu@ufpr.br

${ }^{6}$ Engenheiro Agrônomo, Doutor - Departamento de Fitotecnia e Fitossanitarismo - Universidade Federal do Paraná/UFPR - Rua dos Funcionários, 1540 Juvevê - Cx. P. 19061 - 81531-990 - Curitiba, PR - flazan@ufpr.br
} 
Maytenus ilicifolia Mart. ex Reissek, Celastraceae, conhecida como espinheira-santa, é uma planta medicinal, cujas folhas são utilizadas pela medicina popular para o tratamento de úlceras no estômago e outros problemas gástricos (LORENZI \& MATOS, 2002) e por suas propriedades analgésicas, cicatrizantes das afecções da pele e diurética (KÖRBES, 1995).

A propagação de espinheira-santa pode ocorrer sexuadamente, por sementes, ou assexuadamente, por rebentos nascidos das raízes, estacas caulinares e também por meio da micropropagação. Apesar de apresentarem boa germinação, as plantas oriundas de sementes, apresentam a desvantagem da grande variabilidade quanto à morfologia e ao teor de metabólitos, não havendo garantia quanto às características do material propagado (PEREIRA, 1998).

A estaquia pode ser um método eficiente para a propagação de espinheira-santa e obtenção de material homogêneo, com caracteres genéticos desejáveis, produzidos a partir de plantas matrizes selecionadas (SILVA, 1999). Entretanto, a propagação vegetativa comercial de espinheira-santa por estaquia tem sido limitada por uma série de fatores como escassez de informações sobre a produção de mudas e técnicas de propagação vegetativa e posterior estabelecimento de plantios comerciais da espécie, e a dificuldade de enraizamento de material proveniente de plantas matrizes adultas, mesmo com a aplicação de auxinas, aliada à ausência de informações sobre seus aspectos fisiológicos.

A juvenilidade do material a ser propagado é um dos fatores que mais interfere no processo de enraizamento. As estacas provenientes de plantas matrizes adultas fornecem material vegetativo com maior dificuldade de enraizamento (HARTMANN et al., 2002) e isso se manifesta com mais freqüência em espécies de difícil enraizamento. Possivelmente, esse fato esteja relacionado com o aumento no conteúdo de inibidores e com a diminuição no conteúdo de co-fatores de enraizamento, à medida que aumenta a idade da planta (FACHINELLO et al., 2005). Nesse caso, são necessárias técnicas de rejuvenescimento capazes de resgatar as condições favoráveis ao enraizamento (HIGASHI et al., 2000).

O rejuvenescimento pode ser obtido por técnicas como a poda drástica (CARPANEZZI et al., 2001), anelamento (HARTMANN et al., 2002), propagação seriada via enxertia ou via estaquia e a micropropagação (HIGASHI et al., 2000), ou ainda, pela miniestaquia (WENDLING, 1999).

A miniestaquia é uma técnica recente que vem sendo utilizada com sucesso no processo de propagação clonal em Eucalyptus, que surgiu de um aprimoramento da estaquia para contornar as dificuldades de enraizamento de alguns clones (XAVIER et al., 2003a). Em Eucalyptus sp a propagação clonal pela técnica de miniestaquia já é realidade em várias empresas florestais. Os resultados obtidos com a miniestaquia têm apontado diversas vantagens em relação à estaquia convencional na produção de mudas de Eucalyptus, como a redução da área necessária para a formação do minijardim clonal, redução dos custos com transporte e coleta das brotações, maior eficiência das atividades de manejo, além de proporcionar maior porcentual de enraizamento, qualidade do sistema radicial e velocidade de emissão das raízes (SANTOS et al., 2005; XAVIER et al., 2003b).

O substrato utilizado para o enraizamento de estacas é um fator de grande importância na propagação vegetativa, sendo que o material ideal para a produção de mudas varia de acordo com a espécie a ser propagada e deve permitir um bom suprimento de oxigênio e de água para a base da estaca e para o desenvolvimento de raízes. O substrato mais adequado deve ser inerte, poroso, com boa drenagem e capaz de manter a aeração e a umidade, permitindo o desenvolvimento do sistema radicial (HARTMANN et al., 2002; KAMPF, 2000).

Diante do exposto, objetivou-se, no presente trabalho, avaliar a viabilidade da técnica de miniestaquia na propagação de espinheira-santa (Maytenus ilicifolia), quanto à produção das minicepas e ao enraizamento das miniestacas em diferentes substratos.

Frutos de espinheira-santa foram coletados de plantas matrizes do plantio existente na Estação Experimental do Canguiri, pertencente à Universidade Federal do Paraná, município de Pinhais-PR, no mês de janeiro de 2006. As sementes foram retiradas de frutos maduros, sendo retirado também o arilo de cada uma delas. A semeadura foi realizada no dia seguinte à coleta, em bandeja contendo vermiculita de granulometria fina e mantida em casa-de-vegetação sob irrigação intermitente.

A germinação foi iniciada aos 22 dias e estendeuse até os seis meses após a semeadura. Das plântulas produzidas, 3 meses após a semeadura (abril de 2006), foram selecionadas 300, com altura de aproximadamente 4 a $5 \mathrm{~cm}$, sendo que duas plântulas por vaso foram transplantadas para vasos de polietileno $\left(3000 \mathrm{~cm}^{3}\right)$, contendo a mistura de Plantmax HT $^{\circledR}$ :solo:vermiculita (1:1:1). As plântulas foram mantidas em casa-de-vegetação com fertirrigação quinzenal com $6 \mathrm{~mL}$ de solução aquosa contendo $4 \mathrm{~g} \mathrm{~L}^{-1}$ de sulfato de amônio, $10 \mathrm{~g} \mathrm{~L}^{-1}$ de superfosfato simples, $4 \mathrm{~g} \mathrm{~L}^{-1}$ de cloreto de potássio e $1 \mathrm{~g} \mathrm{~L}^{-1}$ de FTE BR12 (9\% Zn, 3\% Fe, 2\% Mn, $0,1 \% \mathrm{Mo}, 1,8 \% \mathrm{~B}, 0,8 \% \mathrm{Cu})$.

Aos 6 meses e 15 dias após o transplantio, as plântulas com altura variando entre 10 e $35 \mathrm{~cm}$ tiveram seus 
ápices podados a uma altura média de 5 a $10 \mathrm{~cm}$ do colo, mantendo-se dois ou três pares de folhas, para a conversão em minicepas e minijardim clonal.

A contagem de brotações/minicepa foi realizada para a obtenção da produção média do minijardim clonal na primeira coleta. A instalação do experimento foi realizada no início do mês de dezembro (primavera/2006). As miniestacas apicais foram coletadas a partir das brotações das minicepas e confeccionadas com 3 a $4 \mathrm{~cm}$ de comprimento, mantendose duas folhas com a superfície reduzida à metade. Após a coleta, foram acondicionadas em bandeja contendo água para redução das perdas por desidratação. Não foi realizado tratamento fitossanitário. O plantio foi realizado em bandejas contendo areia e em tubetes de polipropileno $\left(53 \mathrm{~cm}^{3}\right)$, contendo casca de arroz carbonizada, Plantmax $\mathrm{HT}^{\circledR} \mathrm{e}$ vermiculita de granulometria fina.

As miniestacas foram mantidas em casa-devegetação com irrigação intermitente com o seguinte intervalo: 15 segundos de rega a cada 15 minutos, das $8 \mathrm{~h}$ às $17 \mathrm{~h} ; 15$ segundos de rega a cada hora, das $17 \mathrm{~h}$ às $23 \mathrm{~h} \mathrm{e}$ 15 segundos a cada 3 horas, das $23 \mathrm{~h}$ às $8 \mathrm{~h}$. Aos 90 dias após o plantio, foram avaliadas as características: porcentagem de estacas enraizadas, vivas com calos, vivas não enraizadas e mortas, número de raízes e comprimento das três maiores raízes formadas por estaca.

Amostras dos substratos utilizados no experimento foram coletadas e mantidas em estufa a $80^{\circ} \mathrm{C}$, durante 12 horas e submetidas a análises físicas, utilizando-se a metodologia de determinação rápida das propriedades físicas de um substrato proposta por Fretz et al. (1979).

O delineamento experimental utilizado foi inteiramente casualizado, com 4 tratamentos e 4 repetições de 22 estacas por parcela. Para testar a homogeneidade das médias, utilizou-se o teste Bartlett e para a comparação de médias, os dados foram submetidos ao teste Tukey, a $5 \%$ de probabilidade. Para a realização da análise estatística foi utilizado o programa MSTAT-Cầ, versão 2.10 (Russel D. Freed, MSTAT Director, Crop and Soil Science Department, Michigan State University, E.U.A).

A produção média de miniestacas de espinheirasanta por minicepa em recipientes contendo $3000 \mathrm{~cm}^{3}$ de substrato foi de 3,58 na primeira coleta, realizada 38 dias após a poda. Esse valor foi superior aos obtidos por Xavier et al. (2003b) cuja produção de miniestacas/minicepa/coleta de cedro-rosa (Cedrela fissilis Vell.) variou de 1,0 a 1,3 com a utilização de tubetes de $55 \mathrm{~cm}^{3}$. Para a espécie vassourão-branco (Vernonanthura petiolaris (A. DC.) H. Rob.) a produção de miniestacas/minicepa/coleta variou de $1,1 \mathrm{a} 2,5$ em recipientes contendo $1700 \mathrm{~cm}^{3}$ de substrato, resultado esse que sugeriria que o aumento da quantidade de substrato poderia promover a produção de maior número de brotações (FERIANI, 2006). Entretanto, resultados divergentes foram obtidos em estudos realizados com Eucalyptus benthamii Maiden \& Cambage (4,1 miniestacas/minicepa a cada 25 a 30 dias) em tubetes (CUNHA et al., 2005), erva-mate (Ilex paraguariensis Saint Hilaire) (4,4 miniestacas/minicepa a cada 39 dias) em sistema semi-hidropônico (WENDLING et al., 2007) e Eucalyptus sp (9,7 miniestacas/minicepa por mês) também em sistema semi-hidropônico (TITON et al., 2003).

Os resultados do teste Bartlett $\left(\div^{2}\right)$ revelaram homogeneidade das variâncias de todas as características analisadas (Tabela 1), exceto para porcentagem de estacas vivas $\left(\dot{\div}^{2}=0,034, \mathrm{CV}=132,56 \%\right)$, não obtida nem por meio da transformação dos dados. A ocorrência de estacas vivas foi verificada apenas no substrato vermiculita $(3,41 \%)$.

Para a variável porcentagem de miniestacas enraizadas de espinheira-santa, os maiores índices de enraizamento foram obtidos com os substratos Plantmax $\mathrm{HT}^{\circledast}(94,31 \%)$, areia $(92,04 \%)$ e casca de arroz carbonizada $(88,63 \%)$, os quais diferiram estatisticamente do substrato vermiculita $(78,41 \%)$ (Tabela 1). O Plantmax HT $^{\circledR}$ é um substrato comercial composto de casca de pinus, turfa e vermiculita. A areia é composta de partículas minerais inertes, com grande porosidade (macroporos) e baixa capacidade de retenção de água (WENDLING et al., 2002), apresentando drenagem rápida e eficiente (KÄMPF, 2000). A casca de arroz carbonizada apresenta boa aeração, por ter alta porcentagem de macroporos e drenagem rápida e eficiente. A vermiculita também possui boa aeração, embora tenha alta retenção de água e reduzida drenagem (KÄMPF, 2002).

Os melhores resultados de enraizamento obtidos nos substratos areia, Plantmax $\mathrm{HT}^{\circledR}$ e casca de arroz carbonizada podem estar relacionados à intolerância da espinheira-santa a substratos ou ambientes encharcados, uma vez que uma maior disponibilidade de oxigênio na base das estacas favorece a atividade celular durante o processo de formação de calos e da emissão de raízes (HARTMANN et al., 2002). No caso do substrato vermiculita verificou-se menor porcentagem de enraizamento $(78,41 \%)$, no entanto, considerada muito boa para a produção comercial de mudas de uma espécie nativa e de crescimento lento. Embora a vermiculita apresente excelente qualidade para o enraizamento de estacas, como por exemplo, a alta aeração (GONÇALVES, 1992; SALVADOR et al., 2001), o fato de apresentar características físicas como reduzida drenagem e alta retenção de água, pode provocar um adensamento em irrigação por longos períodos (KÄMPF, 2002), proporcionando assim, um 
Tabela 1 - Resultados da comparação de médias para as características analisadas em miniestacas de espinheira-santa. UFPR, Curitiba - PR, 2007.

\begin{tabular}{lccccc}
\hline \multicolumn{1}{c}{ Substratos } & ME $(\%)$ & NRE & CRE $(\mathrm{cm})$ & MC $(\%)$ & MM $(\%)$ \\
\hline Areia & $92,04 \mathrm{a}$ & $6,15 \mathrm{a}$ & $1,09 \mathrm{~b}$ & $5,69 \mathrm{ab}$ & $2,27 \mathrm{~b}$ \\
Casca de arroz carbonizada & $88,63 \mathrm{a}$ & $5,37 \mathrm{a}$ & $2,05 \mathrm{a}$ & $9,10 \mathrm{a}$ & $2,28 \mathrm{~b}$ \\
Plantmax HT $^{\circledR}$ & $94,31 \mathrm{a}$ & $7,56 \mathrm{a}$ & $2,75 \mathrm{a}$ & $2,28 \mathrm{~b}$ & $3,41 \mathrm{~b}$ \\
Vermiculita & $78,41 \mathrm{~b}$ & $5,92 \mathrm{a}$ & $2,06 \mathrm{a}$ & $3,41 \mathrm{~b}$ & $14,77 \mathrm{a}$ \\
\hline Média & 88,35 & 6,25 & 1,99 & 5,12 & 5,68 \\
\hline teste Bartlett $\left(\chi^{2}\right)$ & 1,727 & 3,333 & 0,859 & 1,067 & 3,856 \\
\hline CV $(\%)$ & 2,60 & 12,26 & 12,88 & 28,13 & 22,82 \\
\hline
\end{tabular}

Médias seguidas da mesma letra na coluna, não diferem significativamente pelo teste Tukey, a 5\% de probabilidade.

$\mathrm{ME}=$ miniestacas enraizadas; $\mathrm{NRE}=$ número de raízes formadas/estaca; $\mathrm{CRE}=$ comprimento médio de raízes formadas/estaca; $\mathrm{MC}=$ miniestacas com calos; $\mathrm{MM}=$ miniestacas mortas; $\mathrm{CV}=$ coeficiente de variação.

ambiente menos favorável ao desenvolvimento radicial dessa espécie, pois de acordo com Nicoloso et al. (2000), a espinheira-santa suporta temporariamente solos com umidade excessiva.

Tais características são comprovadas pelos resultados apresentados na Tabela 2 , em que o substrato areia $(30,45 \%)$ apresentou baixa capacidade de retenção hídrica, enquanto que a vermiculita $(56,36 \%)$, o Plantmax $\mathrm{HT}^{\circledR}(60,80 \%)$ e a casca de arroz carbonizada $(61,96 \%)$ apresentaram melhor resposta no volume de água retida. Por meio dos resultados, verificou-se menor espaço de aeração quando o substrato estava saturado de água, na areia $(3,55 \%)$ e maior na casca de arroz carbonizada (13,04\%).

A média geral de enraizamento, verificada para miniestacas de espinheira-santa (Maytenus ilicifolia Mart. ex Reissek), no presente experimento, foi de $88,35 \%$ (Tabela 1), sendo essa superior aos resultados obtidos em estudo realizado com estacas herbáceas de espinheira-santa (Maytenus aquifolia Mart.), no qual a maior porcentagem de enraizamento foi de 51,04\% (SILVA, 1999). Em experimento com a aplicação de ácido indolilbutírico (IBA) em miniestacas de vassourão-branco (Vernonanthura petiolaris), Feriani (2006) obteve resultados inferiores, sendo o maior índice de enraizamento observado na testemunha $(27,50 \%)$. No entanto, Tonietto et al. (2001) obtiveram os menores índices de enraizamento de miniestacas de ameixeira (Prunus salicina Lindl.), cultivar Pluma 7 , com a testemunha $(30,00 \%)$, sendo necessária a aplicação de IBA para a promoção do enraizamento.

Os resultados verificados neste trabalho demonstram que a juvenilidade do material utilizado reúne condições favoráveis à indução radicial da espécie em estudo (HARTMANN et al., 2002) e que a produção de mudas de espinheira-santa por meio da técnica de miniestaquia a partir de material de origem seminal é viável, sendo uma alternativa para os produtores e para o estabelecimento de novas áreas de plantio da espécie. Esses resultados concordam com os verificados em experimento realizado com miniestacas de cedro-rosa (Cedrela fissilis), no qual foram obtidas porcentagens de enraizamento de 100 e $98,8 \%$ com miniestacas caulinares e caulinares apicais, respectivamente, confirmando a viabilidade da técnica para a produção de mudas (XAVIER et al., 2003a).

Quanto ao número de raízes formadas por estaca não foi detectada diferença estatística entre os substratos testados, embora o Plantmax $\mathrm{HT}^{\circledR}(7,56)$ tenha se mostrado numericamente superior aos substratos areia $(6,15)$, vermiculita $(5,92)$ e casca de arroz carbonizada $(5,37)$ (Tabela 1). Para a produção comercial, a superioridade numérica observada com Plantmax $\mathrm{HT}^{\circledR}$ pode ser determinante na escolha do substrato, uma vez que um maior volume de raízes significa maior absorção de água e nutrientes, fator esse essencial para o bom desenvolvimento da muda, após o transplantio para o campo. Com relação ao comprimento médio das raízes verificou-se diferença estatística significativa entre os substratos testados, sendo o Plantmax $\mathrm{HT}^{\circledR}(2,75 \mathrm{~cm})$, a vermiculita $(2,06 \mathrm{~cm})$ e a casca de arroz carbonizada $(2,05 \mathrm{~cm})$ superiores à areia $(1,09 \mathrm{~cm})$. As mudas com melhor sistema radicial são melhores ancoradas ao solo no campo, o que possibilita um desenvolvimento mais rápido e vigoroso, além de aumentar as chances de sobrevivência das mesmas (REIS et al., 2000).

Comparando-se as médias para porcentagem de miniestacas com calos (Tabela 1), verificou-se diferença entre os substratos testados, sendo a casca de arroz carbonizada $(9,10 \%)$ estatisticamente superior aos substratos vermiculita $(3,41 \%)$ e Plantmax $\mathrm{HT}^{\circledR}(2,28 \%)$. Os processos de formação de calos e de raízes adventícias são fenômenos independentes, embora ambos envolvam divisão celular e sejam influenciados pelos mesmos fatores, 
Tabela 2 - Determinação das propriedades físicas dos substratos. Curitiba - PR, 2006.

\begin{tabular}{ccccc}
\hline Substratos & $\begin{array}{c}\text { Densidade seca } \\
\left(\mathrm{g} \mathrm{L}^{-1}\right)\end{array}$ & $\begin{array}{c}\text { Porosidade total } \\
(\%)\end{array}$ & Retenção hídrica (\%) & $\begin{array}{c}\text { Espaço de aeração no } \\
\text { substrato saturado (\%) }\end{array}$ \\
\hline Areia & 1510 & 34 & 30,45 & 3,55 \\
Casca de arroz & 187 & 75 & 61,96 & 13,04 \\
Plantmax HT $^{\circledR}$ & 410 & 66 & 60,80 & 5,20 \\
Vermiculita & 230 & 67 & 56,36 & 10,64 \\
\hline
\end{tabular}

podendo ocorrer simultaneamente. Em espécies de difícil enraizamento, a formação de raízes pode ocorrer sobre o calo, embora a formação do mesmo não seja um prenúncio seguro da formação de raízes adventícias (FACHINELLO et al., 2005; HARTMANN et al., 2002). A formação de calos não foi observada em todas as miniestacas de Maytenus ilicifolia, portanto, os primórdios radiciais originaram-se ou não de regiões com calos, não sendo a formação de calos considerada um pré-requisito para a formação de raízes. Esses resultados são concordes com aqueles obtidos por Paes (2002), em estacas de kiwizeiro (Actinidia deliciosa (A. Chev.) C. F. Liang \& A. R. Ferguson), cultivares Bruno, Abbott e Monty.

Os resultados obtidos para a porcentagem de miniestacas mortas demonstraram a superioridade do substrato vermiculita $(14,77 \%)$ na taxa de mortalidade, quando comparado aos demais substratos testados (Tabela 1), embora, comercialmente, esse índice seja considerado baixo. A mortalidade das estacas é variável de acordo com as condições intrínsecas das mesmas e as condições ambientais (HARTMANN et al., 2002), e de acordo com Silva (1999), no caso das estacas herbáceas de espinheira-santa (Maytenus aquifolia), possivelmente os fatores intrínsecos interferiram diretamente na sobrevivência delas.

Outro fator que pode ter interferido na mortalidade das miniestacas é o alto teor de alumínio existente na vermiculita, chegando a $10 \%$ na composição, de acordo com o particulamento, ou seja, quanto menores as partículas maior é a quantidade de alumínio livre ou metálico no substrato (GONÇALVES \& MINAMI, 1994). A absorção de alumínio trocável causa anormalidades no crescimento de espécies cultivadas, em decorrência de danos metabólicos, citológicos e fisiológicos irreversíveis (CODOGNOTTO et al., 2002; PIMENTA et al., 1989). A toxicidade causada pelo alumínio prejudica a absorção e a translocação de nutrientes como o magnésio e o nitrogênio, elementos constituintes da clorofila e dos demais pigmentos fotossintéticos e, conseqüentemente, o processo fotossintético, além desse elemento competir com o cálcio e o magnésio por sítios da parede celular e, principalmente, da membrana plasmática (MILIVOJEVIC \& STOJANOVIC, 2003). Segundo Haag \& Sarruge (1971), não existem evidências de que o alumínio seja um elemento essencial, uma vez que, para determinadas espécies, ele é tóxico, sendo os primeiros sintomas observados no sistema radicular, podendo inclusive levar à morte das raízes.

$\mathrm{O}$ pH é um importante indicador da acidez do substrato, sendo o fator principal de variação de cargas elétricas em solos e substratos. As cargas elétricas negativas do solo, muito conhecidas, são avaliadas pela capacidade de troca de cátions, ou simplesmente CTC, aumentam com a elevação do pH. Já as cargas positivas, quando existem condições para seu aparecimento, variam em sentido inverso, ou seja, aumentam com a diminuição do $\mathrm{pH}$ do solo (RAIJ, 2007). Desse modo, um substrato que possui $\mathrm{pH}$ alcalino, como é o caso da vermiculita (8 11), pode ocasionar problemas de disponibilidade de cálcio, magnésio e micronutrientes como o manganês, zinco, ferro, cobre e boro (RIBEIRO et al., 1999). O presente trabalho baseou-se em análises das características físicas dos substratos, mas as características químicas, principalmente no caso da vermiculita, que possui $\mathrm{pH}$ alcalino e o alto teor de alumínio, apresentam grande influência no sucesso do enraizamento das espécies. Desse modo, o efeito dessas características no enraizamento de espinheira-santa deve ser mais estudado em trabalhos futuros.

A propagação vegetativa de espinheira-santa por meio de miniestaquia e o enraizamento das miniestacas pode ser realizado em substrato Plantmax $\mathrm{HT}^{\circledR}$ ou areia.

\section{REFERÊNCIAS BIBLIOGRÁFICAS}

CARPANEZZI, A. A.; TAVARES, F. R.; SOUSA, V. A. Estaquia de corticeira-do-banhado (Erythrina cristagalli

L.). Colombo: Embrapa, 2001. (Comunicado técnico).

CODOGNOTTO, L. M.; SANTOS, D. M. M.; LEITE, I. C.; MARIN, A.; MADALENO, L. L.; KOBORI, N. N.; BANZATTO, D. A. Efeito do alumínio nos teores de clorofilas de feijão-mungo e labe-labe. Revista

Ecossistema, Espírito Santo do Pinhal, v. 27, n. 1/2, p. $27-$ 30, 2002. 
CUNHA, A. C. M. C. M. da; WENDLING, I.; SOUZA JUNIOR, L. Produtividade e sobrevivência de minicepas de Eucalyptus benthamii Maiden et Cambage. Ciência Florestal, Santa Maria, v. 15, n. 3, p. 307-310, 2005.

FACHINELlO, J. C.; HOFFMANN, A.; NACHTIGAL, J. C. Propagação de plantas frutíferas. Brasília, DF: Embrapa Informação Tecnológica, 2005. 221 p.

FERIANI, A. P. Estaquia de vassourão-branco (Piptocarpa angustifolia Dusén). 2006. 85 f. Dissertação (Mestrado em Agronomia, Produção Vegetal) Universidade Federal do Paraná, Curitiba, 2006.

FRETZ, T. A.; READ, P. E.; PEELE, M. C. Plant propagation laboratory manual. Minneapolis: Burgess, 1979. $317 \mathrm{p}$.

GONÇALVES, A. L. Características de substratos. In: CASTRO, C. E. F. de; ANGELIS, B. D. de; MOURA, L. P. P. de. Manual de floricultura. Maringá: SBPFO, 1992. p. 44-52.

GONÇALVES, A. L.; MINAMI, K. Efeito de substrato artificial no enraizamento de estacas de calanchoe (Kalanchoe x blossfeldiana cv. Singapur, Crassulaceae). Scientia Agricola, Piracicaba, v. 51, n. 2, p. 240-244, 1994.

HAAG, H. P.; SARRUGE, J. R. Nutrição mineral de plantas. Piracicaba: ESALQ, 1971. 187 p.

HARTMANN, H. T. et al. Plant propagation: principles e practices. 7. ed. New Jersey: Prentice Hall, 2002. 880 p.

HIGASHI, E. N.; SILVEIRA, R. L. V. de A.; GONÇALVES, A. N. Propagação vegetativa de Eucalyptus: princípios básicos e sua evolução no Brasil. Circular Técnica IPEF, Piracicaba, n. 192, p. 1-11, 2000.

KÄMPF, A. N. Substrato. In: Produção comercial de plantas ornamentais. Guaíba: Agropecuária, 2000. p. 45-73.

KÖRBES, V. C. Plantas medicinais. Francisco Beltrão: Associação de Estudos, Orientação e Extensão Rural, 1995. 188 p.

LORENZI, H.; MATOS, F. J. de A. Plantas medicinais no Brasil: nativas e exóticas cultivadas. Nova Odessa: Instituto Plantarum, 2002. 512 p.
MILIVOJEVIC, D. B.; STOJANOVIC, D. D. Role of calcium in aluminum toxicity on content of pigments and pigments-protein complexes of soybean. Journal of Plant Nutrition, Filadélfia, v. 26, n. 2, p. 341-350, 2003.

NICOLOSO, F. T.; FORTUNATO, R. P.; ZANCHETTI, F.; CASSOL, L. F.; EISINGER, S. M. Recipientes e substratos na produção de mudas de Maytenus ilicifolia e Apuleia leiocarpa. Ciência Rural, Santa Maria, v. 30, n. 6, p. 987-992, 2000.

PAES, E. da G. B. Enraizamento de estacas de kiwizeiro com fitorreguladores nas quatro estações do ano. 2002. 68 f. Dissertação (Mestrado em Agronomia, Produção Vegetal) - Universidade Federal do Paraná, Curitiba, 2002.

PEREIRA, A. M. S. Micropropagação de Maytenus aquifolium Mart. e Maytenus ilicifolia Mart. (espinheira-santa). In: MING, L. C. (Coord.). Plantas medicinais, aromáticas e condimentares: avanços na pesquisa agronômica. Botucatu: Unesp, 1998. v. 2, p. 19-32.

PIMENTA, J. A.; CAMBRAIA, J.; SANT'ANNA, R.; ESTEVÃO, M. M. Efeito do alumínio sobre algumas enzimas ligadas à assimilação de nitrogênio em sorgo (Sorghum bicolor L. Moench). Revista Brasileira de Fisiologia Vegetal, Campinas, v. 1, n. 2, p. 203-208, 1989.

RAIJ, B. van. Uso de gesso na agricultura: fundamentos e aplicação. 2007. No prelo.

REIS, J. M. R.; CHALFUN, N. N. J.; LIMA, L. C. O.; LIMA, L. C. Efeito do estiolamento e do ácido indolbutírico no enraizamento de estacas do portaenxerto Pyrus calleryana Dcne. Ciência e Agrotecnologia, Lavras, v. 24, n. 4, p. 931-938, 2000.

RIBEIRO, A. C.; GUIMARÃES, P. T. G.; ALVAREZ, V. H. Recomendações para o uso de corretivos e fertilizantes em Minas Gerais: $5^{\text {a }}$ Aproximação. Viçosa: CFSEMG, 1999. $359 \mathrm{p}$.

SALVADOR, E. D.; PASQUAL, M.; SPERA, M. R. N. Efeito de diferentes substratos no crescimento de samambaia-matogrossense (Polypodium aureum L.). Ciência e Agrotecnologia, Lavras, v. 25, n. 4, p. 10061011, 2001. 
SANTOS, A. P. dos; XAVIER, A.; OLIVEIRA, M. L. de; REIS, G. G. dos. Efeito da estaquia, miniestaquia, microestaquia e micropropagação no desempenho silvicultural de Eucalyptus grandis. Scientia

Florestalis, Piracicaba, n. 68, p. 29-38, 2005.

SILVA, C. de P. Efeitos do ANA, ácido bórico, paclobutrazol e da época de coleta, no enraizamento de estacas caulinares de espinheira-santa (Maytenus aquifolia Mart.). 1999. 99 f. Tese (Doutorado em Ciências Biológicas, Botânica) - Universidade Estadual Paulista, Botucatu, 1999.

TITON, M. B.; XAVIER, A.; OTONI, W. C.; REIS, G. G. Efeito do AIB no enraizamento de miniestacas de clones de Eucalyptus grandis W. Hill ex Maiden. Revista Árvore, Viçosa, v. 27, n. 1, p. 1-7, 2003.

TONIETTO, A.; FORTES, G. R. de L.; SILVA, J. B. da. Enraizamento de miniestacas de ameixeira. Revista Brasileira de Fruticultura, Jaboticabal, v. 23, n. 2, p. 373-376, 2001.

WENDLING, I. Propagação clonal de híbridos de Eucalyptus spp. por miniestaquia. 1999. $70 \mathrm{f}$.
Dissertação (Mestrado em Ciência Florestal) Universidade Federal de Viçosa, Viçosa, 1999.

WENDLING, I.; GATTO, A.; PAIVA, H. N.; GONÇALVES, W. Substratos, adubação e irrigação na produção de mudas. Viçosa: Aprenda Fácil, 2002. 165 p. (Coleção jardinagem e paisagismo. Série produção de mudas ornnamentais).

WENDLING, I.; DUTRA, L. F.; GROSSI, F. Produção e sobrevivência de miniestacas e minicepas de erva-mate cultivadas em sistema semi-hidropônico. Pesquisa Agropecuária Brasileira, Brasília, v. 42, n. 2, p. 289-292, 2007.

XAVIER, A.; SANTOS, G. A. dos; OLIVEIRA, M. L. Enraizamento de miniestaca caulinar e foliar na propagação vegetativa de cedro-rosa (Cedrela fissilis Vell.). Revista Árvore, Viçosa, v. 27, n. 3, p. 351-356, 2003.

XAVIER, A.; SANTOS, G. A. dos; WENDLING, I.; OLIVEIRA, M. L. Propagação vegetativa de cedro-rosa por miniestaquia. Revista Árvore, Viçosa, v. 27, n. 2, p. 139-143, 2003. 